\title{
Estrutura, diversidade e distribuição espacial da vegetação arbórea na Floresta Ombrófila Mista em Sistema Faxinal, Rebouças (PR)
}

\author{
Structure, diversity and spatial distribution of trees in the Araucaria Forest \\ in Faxinal System, Rebouças (PR)
}

\author{
Luciano Farinha Watzlawick'(*) \\ Jey Marinho de Albuquerque ${ }^{2}$ \\ Cristina Gouvêa Redin ${ }^{3}$ \\ Régis Villanova Longhi ${ }^{4}$ \\ Solon Jonas Longhi ${ }^{5}$
}

\section{Resumo}

O presente estudo teve por objetivo analisar a estrutura, diversidade e distribuição espacial das espécies arbóreas presentes em uma área de Floresta Ombrófila Mista em Sistema Faxinal no município de Rebouças (PR). O levantamento foi realizado no Faxinal do Salto onde foi instalada uma unidade amostral de 1 ha, a qual foi subdividida em 100 subparcelas de $100 \mathrm{~m}^{2}$ cada. Foram mensurados no total 558 indivíduos com $\mathrm{DAP} \geq 10 \mathrm{~cm}$, pertencentes a 27 espécies arbóreas, distribuídas em 21 gêneros e 17 famílias botânicas. As famílias que apresentaram maior riqueza de espécies foram Myrtaceae e Salicaceae. O índice de diversidade de Shannon-Wiener (H') foi de 2,25 nat.ind ${ }^{-1}$, indicando baixa diversidade florística. $\mathrm{O}$ mesmo ocorre para o índice de Equabilidade de Pielou que resultou em um valor relativamente baixo $(\mathrm{J}=0,68)$.

I Pós-Doutor; Engenheiro Florestal; Professor do Departamento de Agronomia e dos Programas de PósGraduação em Agronomia e Ciências Florestais da Universidade Estadual do Centro-Oeste, UNICENTRO; Bolsista de Produtividade em Pesquisa do CNPq; E-mail: luciano.watzlawick@pq.cnpq.br; Endereço: Rua Simeão Camargo Varela de Sá, 03, Bairro Vila Carli, CEDETEG, CEP: 85040-080, Guarapuava, Paraná, Brasil. (*) Autor para correspondência.

2 MSc.; Engenheiro Ambiental; Diretor do Colégio Estadual Faxinal dos Marmeleiros; Rebouças, Paraná, Brasill; E-mail: jjey2004@yahoo.com.br

3 MSc.; Engenheira Florestal; Mestranda do Programa de Pós-graduação em Engenharia Florestal na Universidade Federal de Santa Maria,UFSM, Santa Maria -, Rio Grande do Sul, Brasil; E-mail:cristina_redin@ yahoo.com.br

4 MSc.; Engenheiro Florestal; Pesquisa e desenvolvimento, Centro de Ciências Rurais, Departamento de Ciências Florestais, Universidade Federal de Santa Maria, UFSM. Santa Maria, Rio Grande do Sul, Brasil; E-mail: regislonghi@yahoo.com.br.

5 Dr.; Engenheiro Florestal; Professor Titular do Departamento de Ciências Florestais da Universidade Federal de Santa Maria, Rio Grande do Sul, Brasil; Bolsisita de Produtividade em Pesquisa do CNPq; E-mail: sjlonghi@smail.ufsm.br. 
Cinnamodendron dinisii e Curitiba prismatica foram às espécies que mais se destacaram na comunidade com $28,5 \%$ e $11,9 \%$, respectivamente, do valor de importância. A análise da estrutura diamétrica da floresta seguiu o padrão das florestas inequiâneas, ou seja, apresentou distribuição exponencial na forma de "J" invertido. O Índice de Payandeh mostrou que a maioria das espécies $(51,9 \%)$ apresentaram comportamento não agregado. Verificou-se ainda que as práticas realizadas no Sistema Faxinal, como a agricultura de subsistência, o extrativismo e principalmente a pecuária em criadouros comunitários, causam a descaracterização da vegetação natural.

Palavras-chave: Fitossociologia; florestas naturais; extrativismo vegetal.

\section{Abstract}

The aim of this study was to analyze the structure, diversity and spatial distribution of tree species present in the Araucarian Forest in Faxinal System in Rebouças city (PR). The survey was conducted in Faxinal do Salto, where it was installed a sampling unit of 1 ha, which was subdivided into 100 subplots of $100 \mathrm{~m}^{2}$ each. It was measured 558 individual trees with $\mathrm{DBH} \geq 10 \mathrm{~cm}$, belonging to 27 tree species distributed among 21 genders and 17 families. The botanical families with highest species richness were Myrtaceae and Salicaceae. The Shannon's diversity index was 2.25 nat.ind-1, indicating a low floristic diversity. The same occurred for Pielou's equability index, which resulted a relative low value $(\mathrm{J}=0.68)$. Cinnamodendron dinisii and Curitiba prismatica were the highlighted species in the community with $28.5 \%$ and $11.9 \%$, respectively, in importance value. The analysis of the forest diametric structure followed the pattern of natural forests, in other words, it presented exponential distribution in the form of an inverted "J". The Payandeh's Index indicated that most species (51.9\%) presented no aggregated behavior. It was also found that the practices carried out by Faxinal system, such as subsistence agriculture, extrativism and mainly animal husbandry in communitarian barns, cause the uncharacterization of the natural vegetation.

Key words: Phytossociology; natural forests; extractivism vegetable.

\section{Introdução}

No Estado do Paraná, dentre as diferentes regiões fitogeográficas, destacase a região da Floresta Ombrófila Mista ou Floresta com Araucária, a qual cobria originalmente cerca de $200.000 \mathrm{~km}^{2}$ em todo o Brasil, ocorrendo nos Estados do Paraná (40\% de sua superfície), Santa Catarina (31\%) e Rio Grande do Sul (25\%), além de manchas esparsas no Estado de São Paulo (3\%), adentrando até o sul do Estado de Minas Gerais e Rio de Janeiro (1\%) (CARVALHO, 1994). Entretanto, segundo dados da FUPEF (2001), a Floresta Ombrófila Mista iniciou o novo milênio com apenas $0,8 \%$ de seus remanescentes naturais em estágio avançado de sucessão, fragmentados ao longo dos três planaltos do Estado do Paraná.

As porções do Estado do Paraná que abrangem as meso-regiões Centro-Sul e Sudeste têm suas características singulares 
por apresentar uma forma de organização camponesa única, conhecida como Sistema Faxinal. Conforme Chang (1988), popularmente a palavra "Faxinal" significa mata densa, porém, etimologicamente, significa mata rala com vegetação variada. Os Faxinais se encontram nessa região por mais de 200 anos, produzindo e reproduzindo suas relações através do extrativismo vegetal da erva-mate, da madeira e do pinhão, a criação de animais à solta para o consumo interno e a policultura alimentar, tanto para o comércio como para o próprio consumo (BARRETO, 2008).

De acordo com o Decreto Estadual $n^{\circ}$ 3.446/97 define-se Faxinal como "um sistema de produção camponês tradicional, característico da região Centro-Sul do Paraná, que tem como traço marcante o uso coletivo da terra para produção animal e a conservação ambiental". Assim, a forma de produção denominada Sistema Faxinal concilia as atividades de subsistência, baseada na agricultura familiar, com atividades agrossilvipastoris e a conservação ambiental, incluindo a proteção do pinheiro (Araucaria angustifolia (Bertol.) Kuntze), que juntamente com a erva-mate (Ilex paraguariensis A.St.Hil), caracterizam a vegetação local, hoje, com remanescentes extremamente ameaçados (PARANÁ, 1997).

Conforme decreto o Sistema Faxinal fundamenta-se em três componentes: produção animal - criação coletiva à solta nas áreas dos criadouros comunitários; produção agrícola - agricultura de subsistência, com comercialização do excedente; e extrativismo florestal de baixo impacto - manejo de ervamate (Ilex paraguariensis), pinheiro (Araucaria angustifolia), e outras espécies nativas.

O modo de produção capitalista que vigora nos dias atuais tem exercido uma forte pressão sobre os sistemas faxinais, sobretudo no que se refere ao conflito de uso do espaço rural. A opção entre conservação ou desenvolvimento, gerou um intenso processo de desagregação na sua forma de organização, principalmente nos anos 70 , onde este processo se aprofundou ainda mais, estimulado pela coação do segmento mais capitalizado e tecnificado da agricultura sobre o recurso Terra (SILVA, 2005).

A estrutura da Floresta Ombrófila Mista é complexa e os conhecimentos sobre os diversos tipos de comunidades, que existem dentro de sua área de distribuição natural, ainda não permitem uma política de conservação eficiente que mantenha a maior parte de sua diversidade vegetal pouco conhecida (NASCIMENTO et al., 2001). Para Watzlawick et al. (2008), a caracterização dos componentes de uma floresta, assim como dos processos resultantes da interação entre eles, são fundamentais para conhecer o seu funcionamento, avaliar as implicações qualitativas e quantitativas da interferência antrópica na sua auto-sustentabilidade.

O estudo da fitossociologia visa, segundo Klein (1960), a descrição da composição e estrutura das associações, determinação dos locais preferenciais das espécies características, além da análise do seu comportamento nos diferentes ambientes da floresta. $\mathrm{O}$ conhecimento do padrão de distribuição espacial pode fornecer informações sobre a ecologia, subsidiar a definição de estratégias de conservação, auxiliar em processos de amostragem ou simplesmente esclarecer a estrutura espacial de uma espécie (ANJOS et al., 1998). Da mesma forma, Capretz (2004) salienta que investigar o padrão espacial das árvores, segundo suas espécies mais abundantes, pode fornecer evidências sobre a estrutura da comunidade.

Diante das considerações anteriores, no presente estudo foram avaliadas a composição 
florística, estrutura e diversidade da vegetação, além dos padrões de distribuição espacial das espécies no Faxinal do Salto, município de Rebouças - Paraná.

\section{Material e Métodos}

\section{Caracterização da área de estudo}

A Floresta Ombrófila Mista em Sistema Faxinal do presente estudo, localizase no Faxinal do Salto, município de Rebouças-PR (Figura 1), nas coordenadas $25^{\circ} 37^{\prime} 15^{\prime \prime}$ de latitude Sul e 50 41'34" de longitude Oeste, a uma altitude média de $815 \mathrm{~m}$.

O clima da região, segundo a classificação de Köppen, é Cfb - Subtropical Úmido Mesotérmico, com verões frescos, sem estações secas e com geadas. A precipitação média anual fica entre 1500 e $1600 \mathrm{~mm}$ (SUDERHSA, 1998) e a temperatura média anual é de aproximadamente $18{ }^{\circ} \mathrm{C}$, com mínima de $-2{ }^{\circ} \mathrm{C}$ e máxima de $32{ }^{\circ} \mathrm{C}$.

O substrato geológico da região é formado pelo derrame de Trapp da formação basáltico (EMBRAPA, 1984), apresentando relevo desde plano, ondulado e montanhoso, sendo o último de maior predominância (EMBRAPA, 1999). Os solos de maior ocorrência são Neossolos Litólicos, Cambissolos e Argissolos (PARANÁ, 1987).

Segundo Gubert Filho (1987), as características climáticas e a forma do relevo da região fazem com que a vegetação seja descrita como um ambiente florestal que abriga espécies típicas da Floresta Ombrófila Mista, como o pinheiro-brasileiro (Araucaria angustifolia (Bertol.) Kuntze), erva-mate (Ilex paraguariensis A.St.-Hil.), canelas (Nectandra sp.), imbúia (Ocotea porosa (Nees \& Mart.) Barroso), canela-lageana (Ocotea pulchella (Nees \& Mart.) Mez), e o pinheiro-bravo (Podocarpus lambertii Klotzsch ex End1.).

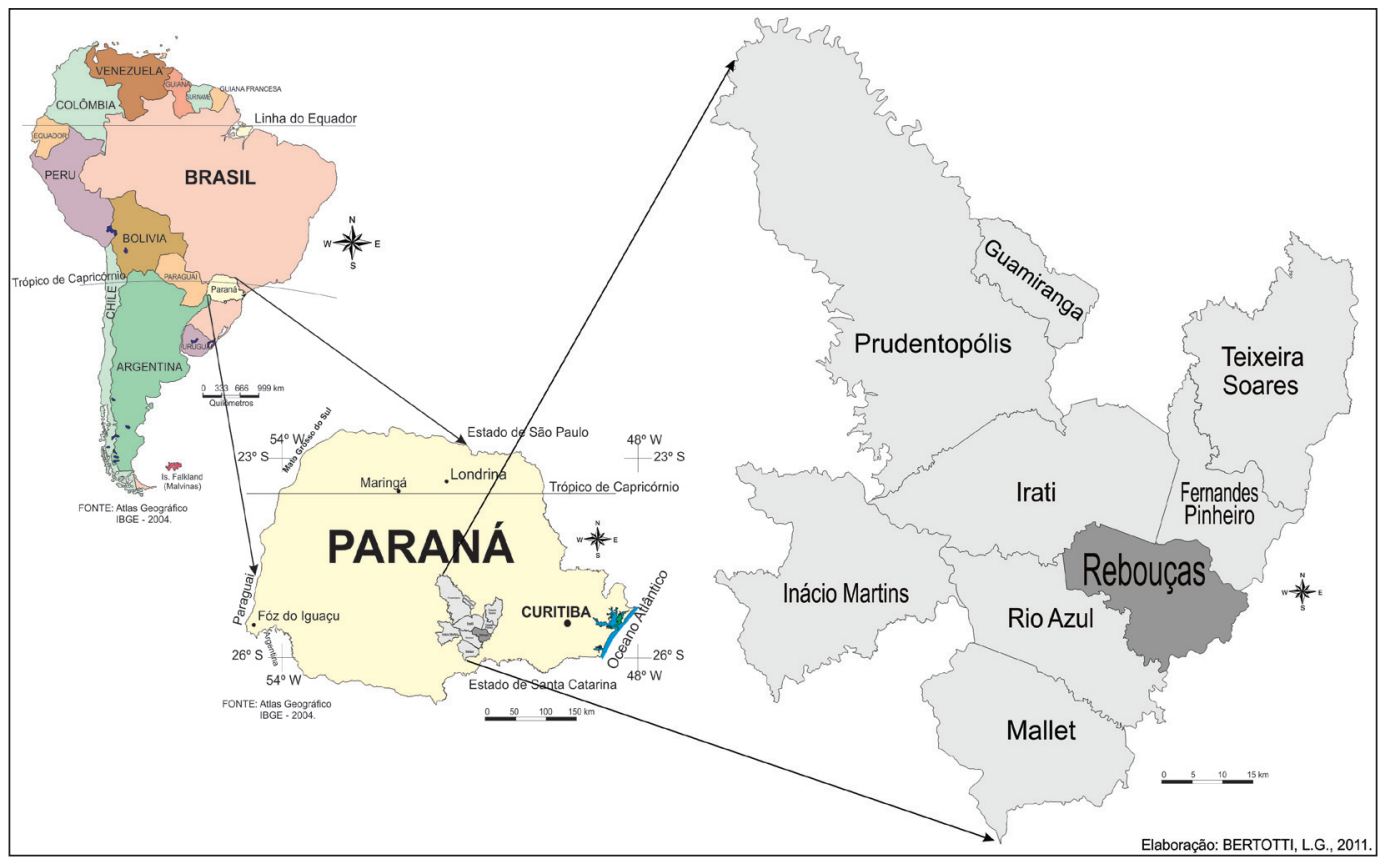

Figura I. Localização do Município de Rebouças (PR) Brasil 
Amostragem,coleta e análise dos dados

Os dados foram coletados em uma unidade permanente de 1 ha de área (100 x 100 m), instalada no Faxinal do Salto, sendo cada unidade foi subdividida em 100 subunidades contíguas de $100 \mathrm{~m}^{2}$ $(10 \times 10 \mathrm{~m})$. Em cada subunidade foram medidos todos os indivíduos com diâmetro a altura do peito $(\mathrm{DAP}) \geq 10 \mathrm{~cm}$. Além da identificação botânica das espécies, os indivíduos levantados foram numerados com etiqueta de metal e espacializados na área através de um sistema de coordenadas $\mathrm{X}$ e
Y. Todas as espécies amostradas seguiram o enquadramento sistemático pelo Sistema de Classificação APG-II (APG - II, 2003).

Os dados coletados a campo foram ordenados e processados por meio do Software "Mata Nativa 2" (CIENTEC, 2006). As estimativas fitossociológicas calculadas foram: densidade, frequência, dominância, valor de importância e valor de cobertura (MUELLER-DOMBOIS; ELLENBERG, 1974). Além dessas, foram também calculados o Índice de Diversidade de Shannon-Wiener - H (SHANNON; WIENER, 1949), Índice de Equabilidade de Pielou

Tabela I. Relação de espécies vegetais amostradas em Floresta Ombrófila Mista em Sistema Faxinal. Faxinal do Salto, Rebouças (PR)

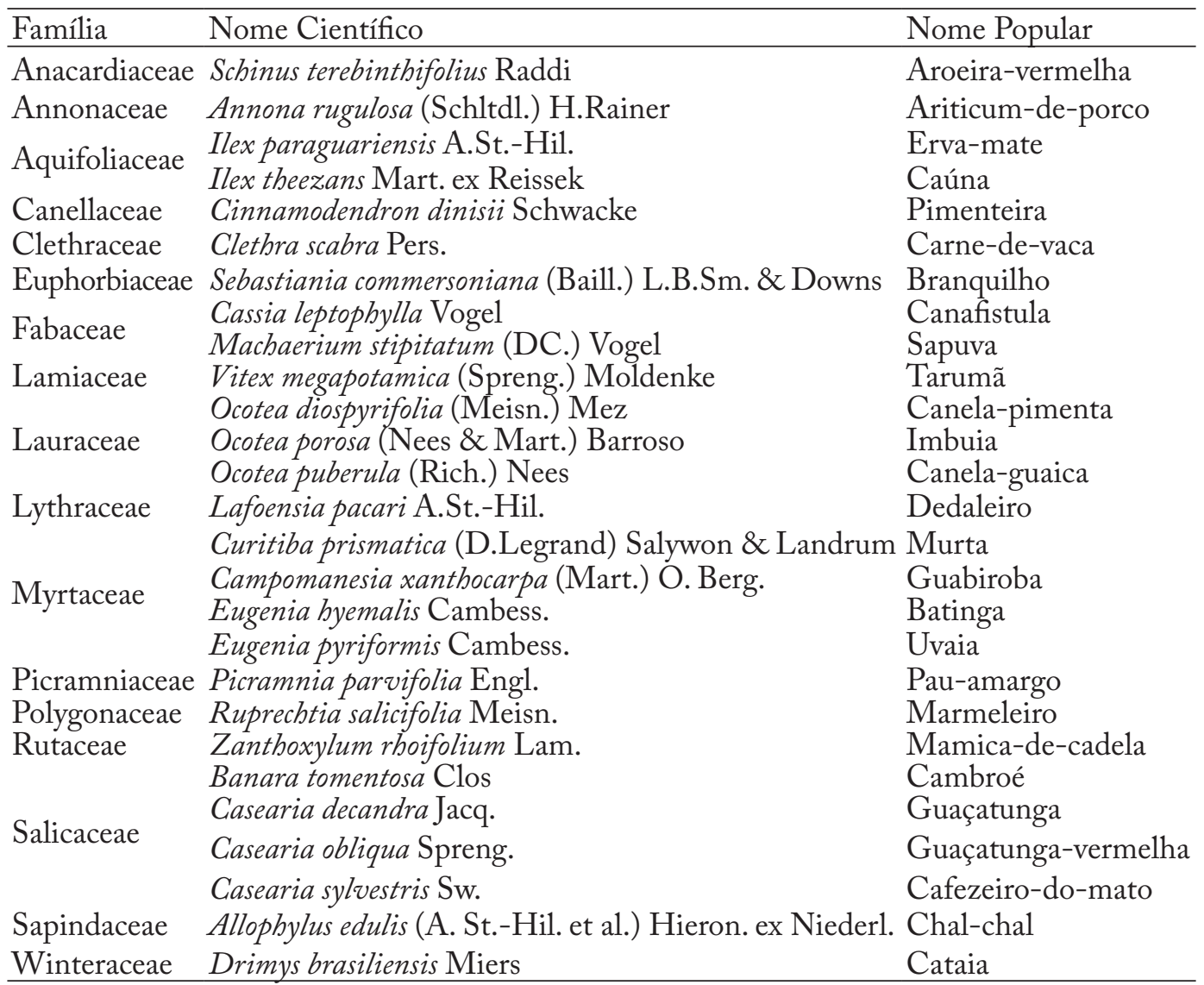


- J (PIELOU, 1977) e Índice de Agregação de Payandeh (PAYANDEH, 1970).

Para o índice de Agregação de Payandeh, a classificação do padrão de distribuição espacial dos indivíduos obedece a seguinte escala: $\mathrm{Pi}<1$ (distribuição aleatória); $1 \leq \mathrm{Pi} \leq 1,5$ (tendência ao agrupamento) e $\mathrm{Pi}>1,5$ (distribuição agregada ou agrupada). As espécies com menos de dois indivíduos nas amostras foram desconsideradas por apresentarem sempre distribuição nãoagrupada.

A análise da estrutura populacional da vegetação arbórea consistiu na elaboração de histograma, cujos intervalos de classes foram definidos pela fórmula $\mathrm{A} / \mathrm{K}$, onde A representa a amplitude para o parâmetro (diâmetro ou altura) e K é definido pelo algoritmo de Sturges $(K=1+3,3 x \log (n))$, sendo $\mathrm{n}=$ número de indivíduos amostrados .

\section{Resultados e Discussão}

\section{Diversidade Florística e Estrutura da Floresta}

Foram mensurados 558 indivíduos com DAP $\geq 10$ centímetros, pertencentes a 27 espécies arbóreas, distribuídas em 21 gêneros e 17 famílias botânicas (Tabela 1). As famílias que evidenciaram a maior riqueza de espécies foram: Myrtaceae (4), Salicaceae (4), Lauraceae (3), Fabaceae e Aquifoliaceae, ambas com duas espécies cada, representando $76,5 \%$ das espécies amostradas. Em trabalho realizado por Sawczuk (2009) utilizando a mesma classe diamétrica objetivando verificar a alteração da composição florística na Flona de Irati, o autor constatou que no ano de 2008 a mesma possui 567 indivíduos/ ha divididos em 116 espécies, 78 gêneros, pertencentes a 44 famílias botânicas. As diferenças em relação ao trabalho de Sawczuk (2009), bem como de outros trabalhos estão relacionadas principalmente a preservação, ao nível de inclusão e ao estágio de sucessão que se encontra a floresta.

Por outro lado, aproximadamente $70,6 \%$ das famílias, ou seja, 12 das 17 famílias evidenciadas estão representadas na floresta por uma única espécie. Em relação à porcentagem de indivíduos encontrados em cada família pode-se dizer que Canellaceae, com uma única espécie, se destacou compondo 30,6\% do total de indivíduos da área. As demais foram: Salicaceae (19,2\%), Myrtaceae (17,6\%) e Annonaceae (13,4\%).

Em estudo realizado por Watzlawick et al. (2008) na região de Rebouças (PR), em Sistema Faxinal na área do Faxinal Marmeleiro de Cima, foram encontrados resultados semelhantes aos do presente estudo para a diversidade florística, destacando-se as famílias Myrtaceae, Salicaceae, Aquifoliaceae e Fabaceae. O diferencial foi a família Lauraceae que se mostrou mais representativa em Faxinal do Salto. Nascimento et al. (2001) determinaram maior número de espécies para a família Myrtaceae em Floresta Ombrófila Mista. Segundo Longhi et al. (2006) é comum a família Myrtaceae estar entre as mais representativas neste tipo florestal.

De acordo com o índice de diversidade de Shannon-Wiener $\left(H^{\prime}\right)$, a área apresentou baixa diversidade florística, com valores de 2,25 nat.ind ${ }^{-1}$. No estudo feito por Nascimento et al. (2001), utilizando a mesma intensidade amostral do presente estudo, em uma floresta secundária pertencente aos domínios de Floresta Ombrófila Mista localizada em Nova Prata, RS, foi encontrado um valor de $\mathrm{H}^{\prime}=3,0$, indicando uma diversidade mediana esperada para esse tipo de formação florestal. 
Tabela 2. Estimativas dos parâmetros fitossociológicos para as espécies arbóreas amostradas em Floresta Ombrófila Mista em Sistema Faxinal. Faxinal do Salto, Rebouças (PR)

\begin{tabular}{|c|c|c|c|c|c|c|c|c|}
\hline Espécie & $\mathrm{DA}$ & $\mathrm{DR}$ & $\mathrm{FA}$ & FR & DoA & DoR & $\mathrm{VC}(\%)$ & VI (\%) \\
\hline Cinnamodendron dinisii & 171 & 30,7 & 73 & 23,93 & 5,83 & 30,94 & 30,79 & 28,51 \\
\hline Curitiba prismatica & 90 & 16,1 & 39 & 12,79 & 1,28 & 6,79 & 11,46 & 11,90 \\
\hline Annona rugulosa & 75 & 13,4 & 35 & 11,48 & 1,22 & 6,47 & 9,96 & 10,46 \\
\hline Ocotea puberula & 31 & 5,56 & 24 & 7,87 & 3,16 & 16,76 & 11,16 & 10,06 \\
\hline Casearia obliqua & 55 & 9,86 & 32 & 10,49 & 1,23 & 6,54 & 8,20 & 8,96 \\
\hline Casearia decandra & 47 & 8,42 & 28 & 9,18 & 1,27 & 6,73 & 7,58 & 8,11 \\
\hline Ocotea diospyrifolia & 3 & 0,54 & 3 & 0,98 & 1,53 & 8,10 & 4,32 & 3,21 \\
\hline Picramnia parvifolia & 18 & 3,23 & 14 & 4,59 & 0,33 & 1,74 & 2,49 & 3,19 \\
\hline Ruprechtia salicifolia & 12 & 2,15 & 9 & 2,95 & 0,38 & 2,04 & 2,09 & 2,38 \\
\hline Drimys brasiliensis & 8 & 1,43 & 8 & 2,62 & 0,22 & 1,14 & 1,29 & 1,73 \\
\hline Allophylus edulis & 7 & 1,25 & 6 & 1,97 & 0,27 & 1,41 & 1,33 & 1,54 \\
\hline Vitex megapotamica & 6 & 1,08 & 4 & 1,31 & 0,26 & 1,40 & 1,24 & 1,26 \\
\hline Ocotea porosa & 2 & 0,36 & 2 & 0,66 & 0,34 & 1,80 & 1,08 & 0,94 \\
\hline Ilex paraguariensis & 4 & 0,72 & 4 & 1,31 & 0,13 & 0,71 & 0,71 & 0,91 \\
\hline Espécies mortas & 3 & 0,54 & 3 & 0,98 & 0,17 & 0,92 & 0,73 & 0,81 \\
\hline Cassia leptophylla & 2 & 0,36 & 2 & 0,66 & 0,22 & 1,18 & 0,77 & 0,73 \\
\hline Lafoensia pacari & 1 & 0,18 & 1 & 0,33 & 0,27 & 1,42 & 0,80 & 0,64 \\
\hline Eugenia pyriformis & 4 & 0,72 & 1 & 0,33 & 0,15 & 0,79 & 0,75 & 0,61 \\
\hline Clethra scabra & 2 & 0,36 & 2 & 0,66 & 0,13 & 0,71 & 0,53 & 0,57 \\
\hline Zanthoxylum rhoifolium & 3 & 0,54 & 3 & 0,98 & 0,03 & 0,15 & 0,35 & 0,56 \\
\hline Schinus terebinthifolius & 2 & 0,36 & 2 & 0,66 & 0,12 & 0,66 & 0,51 & 0,56 \\
\hline Campomanesia xanthocarpa & 2 & 0,36 & 2 & 0,66 & 0,12 & 0,66 & 0,51 & 0,56 \\
\hline Casearia sylvestris & 3 & 0,54 & 2 & 0,66 & 0,03 & 0,14 & 0,34 & 0,44 \\
\hline Banara tomentosa & 2 & 0,36 & 2 & 0,66 & 0,04 & 0,19 & 0,28 & 0,40 \\
\hline Eugenia byemalis & 2 & 0,36 & 1 & 0,33 & 0,05 & 0,28 & 0,32 & 0,32 \\
\hline Sebastiania commersoniana & 1 & 0,18 & 1 & 0,33 & 0,03 & 0,17 & 0,17 & 0,22 \\
\hline Machaerium stipitatum & 1 & 0,18 & 1 & 0,33 & 0,02 & 0,11 & 0,14 & 0,20 \\
\hline Ilex theezans & 1 & 0,18 & 1 & 0,33 & 0,01 & 0,05 & 0,11 & 0,19 \\
\hline TOTAL & 558 & 100 & 305 & 100 & 18,83 & 100 & 100 & 100 \\
\hline
\end{tabular}

Nota: $D A=$ densidade absoluta (ind $h^{-1}$ ); $D R=$ densidade relativa (\%); $F A=$ frequência absoluta (\%); $F R=$ frequência relativa (\%); DoA = dominância absoluta $\left(\mathrm{m}^{2} \mathrm{ha}^{-1}\right) ; \mathrm{DoR}=$ dominância relativa (\%);VC\% = valor de cobertura;Vl\% = valor de importância.

O índice de equabilidade de Pielou (J) resultou em um valor relativamente baixo $\mathrm{J}=0,68$ no fragmento de Floresta Ombrófila Mista amostrado, indicando uniformidade média entre os indivíduos e as espécies. Para Barddal et al. (2003) em estudo realizado no Sub-bosque de Floresta Ombrófila Mista Aluvial pertencente ao município de Araucária no Paraná foi encontrado o mesmo valor para o Índice de 
Equabilidade de Pielou $(0,68)$. Ramos et al. (2008) encontraram para um remanescente de Floresta Ombrófila Mista Aluvial em Lages, SC, um valor de 0,86 , diferindo do presente estudo, e demonstrando que há uma distribuição relativamente equilibrada entre os indivíduos da área.

As estimativas dos parâmetros fitossociológicos das espécies do Faxinal do Salto estão demonstrados na tabela 2. Foram encontrados 558 indivíduos no hectare amostrado, sendo que destes, $78,5 \%$ estão distribuídos em apenas três espécies: Cinnamodendron dinisii, Curitiba prismatica, e Annona rugulosa. Essas três espécies, juntamente com Ocotea puberula, Casearia obliqua e Casearia decandra, perfazem um total de 78,0\% do total do valor de importância das espécies. Desse total, Cinnamodendron dinisii é a que mais se destacou na comunidade com $28,5 \%$.

Em estudo realizado por Albuquerque (2009), em duas áreas sob sistema faxinal, ambos em Rebouças (PR), foi encontrado resultados semelhantes aos do presente estudo apenas para o Faxinal Marmeleiro de Cima, onde foi encontrado Casearia obliqua e Cinnamodendron dinisii as espécies de maior valor de importância.Já para no Faxinal Marmeleiro de Baixo, o autor encontrou Curitiba prismatica como a espécie mais importante, seguida por Campomanesia xanthocarpa, porém não foi encontrado nenhum indivíduo de Cinnamodendron dinisii, diferindo do presente estudo, a qual figura como a espécie de maior valor de importância.

Pela dominância as espécies com maior área basal por hectare foram: Cinnamodendron dinisii, Ocotea puberula, Ocotea dyospirifolia, Curitiba prismatica, Casearia decandra, Casearia obliqua e Annona rugulosa. Juntas, essas sete espécies totalizam $82,3 \%$ da dominância relativa, ou seja, contribuem com
15,5 $\mathrm{m}^{2}$.ha ${ }^{-1}$ do total de $18,8 \mathrm{~m}^{2}$.ha ${ }^{-1}$ de área basal encontrada no Sistema Faxinal.

Cabe ressaltar que para o presente estudo as árvores mortas ocuparam uma posição intermediária no valor de importância. Em se tratando de Floresta Ombrófila Mista, segundo o Inventário Florestal Contínuo do Rio Grande do Sul (RIO GRANDE DO SUL, 2002), as árvores mortas são significativas na composição das comunidades e estão presentes sempre nas primeiras posições no valor de importância. Essa discrepância pode ser explicada pelo aproveitamento que as famílias residentes no sistema faxinal fazem desses indivíduos mortos, tanto para lenha como para construção de benfeitorias próprias.

Foi observado que a vegetação dos faxinais encontra-se descaracterizada e de certa forma degradada devido à ausência de indivíduos de Araucaria angustifolia ( $\mathrm{Pi}^{-}$ nheiro-brasileiro) e ao reduzido número de indivíduos mensurados de Ilex paraguariensis (Erva-mate), espécies típicas da Floresta Ombrófila Mista. Esse fato, provavelmente, é consequência dos impactos causados pela ação antrópica do Sistema Faxinal, pois essas comunidades adotam como práticas comuns o extrativismo, agricultura de subsistência e a pecuária em criadouros comunitários com a presença de animais em seu interior, bem como a extração de forma seletiva concentrou a exploração madeireira de maior valor econômico sob o pinheiro (Araucaria angustifolia), a imbuia (Ocotea porosa), a canela-guaica (Ocotea puberula), a canela-lageana (Ocotea pulchella), o cedro (Cedrela fissilis), fato este constatado pela inobservância de regularidade e frequência de tais espécies na área.

Em relação à estrutura diamétrica, do conjunto das 558 árvores mensuradas no sistema faxinal, foram obtidas dez classes 
diamétricas com intervalos fixos de $8 \mathrm{~cm}$. O número de árvores por classe diamétrica, bem como o intervalo de classe, é visualizado na figura 2.

$\mathrm{Na}$ figura 2, observa-se que o comportamento segue o padrão característico de florestas naturais inequiâneas, ou seja, apresenta uma distribuição exponencial negativa (MEYER, 1952) na forma de "J" invertido, sendo que a maior frequência de indivíduos se encontra nas classes de diâmetros menores. Para Longhi (1980), esse tipo de distribuição garante que o processo dinâmico da floresta se perpetue, pois a súbita ausência de indivíduos dominantes dará lugar para as chamadas "arvores de reposição".

Da vegetação amostrada, 65,6\% dos indivíduos apresentaram DAP entre

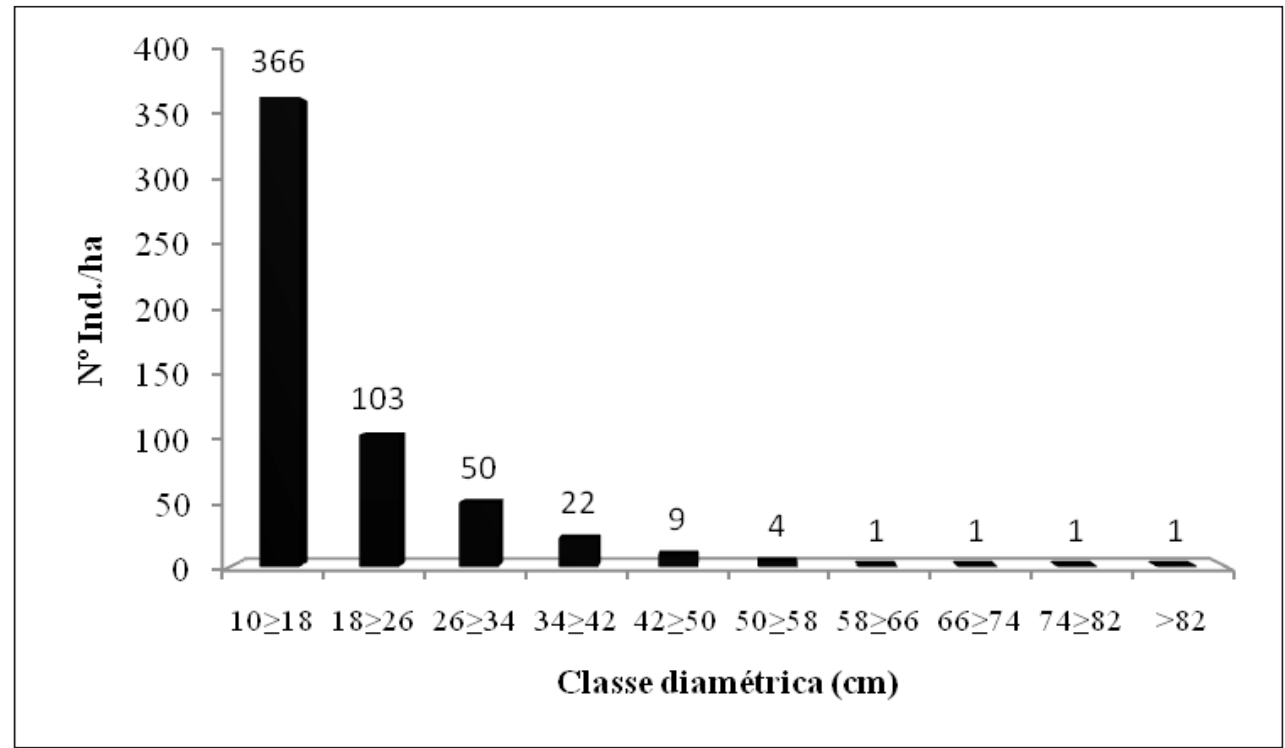

Figura 2. Distribuição de frequência por classe diamétrica para os indivíduos arbóreos com DAP $\geq$ $10 \mathrm{~cm}$ na Floresta Ombrófila Mista em Sistema Faxinal. Faxinal do Salto, Rebouças (PR)

10 e $18 \mathrm{~cm}$. Já nas quatro ultimas classes diamétricas foi observada a presença de apenas um indivíduo em cada classe. Esse fato provavelmente é consequência da extração madeireira que ocorreu na região no século XX. Segundo Albuquerque (2009) por várias décadas o extrativismo florestal foi a base da economia paranaense, devido à existência em seu território de espécies de grande valor econômico, como o pinheiro (Araucaria angustifolia), imbúia (Ocotea porosa), erva-mate (Ilex paraguariensis), entre outras.

\section{Distribuição Espacial}

Para a obtenção do grau de agregação das espécies, por meio do índice de Payandeh $(P i)$, foram consideradas dezesseis espécies as quais apresentaram mais de dois indivíduos amostrados. A tabela 3 mostra os resultados obtidos. Pode-se observar que duas espécies apresentaram-se fortemente agregadas, conforme Tabela 3 Curitiba prismatica (Murta) e Eugenia pyriformis (Uvaia), essa ultima apesar de não possuir alta densidade, obteve esse resultado devido a todos os indivíduos estarem presentes em uma única 
Tabela 3. Distribuição espacial para as espécies arbóreas com mais de dois indivíduos amostrados em Floresta Ombrófila Mista em Sistema Faxinal. Faxinal do Salto, Rebouças (PR)

\begin{tabular}{lcc}
\hline Nome Científico & $\mathbf{P i}$ & Classif. Pi \\
\hline Curitiba prismatica & 4,01 & Agrupado \\
Eugenia pyriformis & 4,00 & Agrupado \\
Annona rugulosa & 2,22 & Agrupado \\
Casearia obliqua & 1,78 & Agrupado \\
Casearia decandra & 1,70 & Agrupado \\
Casearia sylvestris & 1,65 & Agrupado \\
Vitex megapotamica & 1,62 & Agrupado \\
Cinnamodendron dinisii & 1,60 & Agrupado \\
Ruprechtia salicifolia & 1,56 & Agrupado \\
Pricamnia parvifolia & 1,39 & Tend. Agrup. \\
Ocotea puberula & 1,28 & Tend. Agrup. \\
Allophylus edulis & 1,23 & Tend. Agrup. \\
Ocotea diospyrifolia & 0,98 & Não Agrup. \\
Zanthoxylum rhoifolium & 0,98 & Não Agrup. \\
Ilex paraguariensis & 0,97 & Não Agrup. \\
Drimys brasiliensis & 0,93 & Não Agrup. \\
\hline
\end{tabular}

parcela. Com exceção dessas duas espécies, as demais apresentaram valores relativamente baixos de agregação.

Considerando-se para análise essas dezesseis espécies, os resultados da Tabela 3 demonstram de um modo geral que poucas espécies apresentaram tendência ao agrupamento, apenas $11,1 \%$, enquanto que $51,9 \%$ apresentaram-se não agrupadas e 37,0\% agrupadas. Segundo Bleher e Böhning-Gaese (2001), o padrão agregado pode estar relacionado a uma distribuição mais localizada de micro-sítios favoráveis ao estabelecimento de plântulas, bem como deve-se ressaltar que nos criadouros comunitários os animais vivem soltos, e os mesmos possuem uma certa seletividade com relação ao pastoreio em detrimento de outras.

Já as espécies aleatórias, segundo Nascimento et al. (2001), ocorrem mais espalhadas na vegetação, com menores valores das médias no número de indivíduos e baixos valores da Razão Variância/Média (geralmente menores que um) e podem, em determinados casos, apresentarem problemas de regeneração natural.

O grande número de espécies distribuídas na área na forma não agregada ou aleatória mais uma vez demonstra que a floresta em estudo encontra-se descaracterizada. Esse fato é devido principalmente ao sistema de manejo da floresta com a presença de animais em seu interior, alterando a dinâmica da vegetação, dificultando a regeneração e o crescimento da floresta.

\section{Conclusões}

O fragmento de Floresta Ombrófila Mista amostrado em Sistema Faxinal mostra-se estar descaracterizado devido ao fato de ter apresentado valores relativamente baixos para os índices de diversidade e equabilidade, além de baixa densidade de indivíduos encontrados, principalmente de 
Ilex paraguariensis e a não observância de nenhum exemplar de Araucaria angustifolia, espécies características dessa fisionomia.

As espécies com maior valor de importância na área foram: Cinnamodendron dinisii, Curitiba prismatica, Annona rugulosa e Ocotea puberula.Já Myrtaceae e Salicaceae se firmaram como famílias de maior riqueza de espécies.
A estrutura diamétrica da vegetação demonstra que a maior parte dos indivíduos se encontra em classes com diâmetros menores. O comportamento segue a distribuição de "J" invertido, característico de florestas inequiâneas, denotando uma comunidade com potencial de regeneração e com muitos indivíduos jovens em relação ao número de indivíduos adultos.

\section{Referências}

ALBUQUERQUE, J. M. Florística, estrutura e aspectos físicos de Floresta Ombrófila Mista em Sistema Faxinal no município de Rebouças, Paraná. 2009. 92 f. Dissertação (Mestrado em Engenharia Florestal) - Universidade Estadual do Centro-Oeste, UNICENTRO, Paraná, 2009.

ANJOS, A.; COUTO, H.T.Z.; BATISTA,J. L.F.; REIS, A. Análise do efeito de um manejo em regime de rendimento sustentável sobre o padrão de distribuição espacial do palmiteiro (Euterpe edulis Martius), utilizando a função K de Ripley. Revista Árvore, Viçosa, v.22, p.215-225, 1998.

APG II. The Angiosperm Phylogeny Group II. An update of the angiosperm phylogeny group classification for the orders and families of higher plants. Botanical Journal of the Linean Society, London, v.141, p.399-436, 2003.

BARDDAL, M. L.; RODERJAN, C. V.; GALVÃO, F.; CURCIO, G. R. Fitossociologia do Sub-bosque de uma Floresta Ombrófila Mista Aluvial no município de Araucária, PR. Ciência Florestal, Santa Maria, v.14, n.1, p.35-45, 2003.

BARRETO, M. A produção camponesa e monopólio do território pelo capital: Espacialidades distintas na extração da Erva-mate na região da Floresta com Araucária do Paraná. 2008. 44f. Dissertação (Mestrado em Geografia) - Universidade Estadual de Ponta Grossa, UEPG, Paraná, 2008.

BLEHER, B.; BÖHNING-GAESE, K. Consequences of frugivore diversity for seed dispersal, seedling establishment and the spatial pattern of seedlings and trees. Oecologia, Berlin, v. 129, p.385-394. 2001.

CAPRETZ, R. L. Análise dos padrões espaciais de árvores em quatro formações florestais do estado de São Paulo, através de análises de segunda ordem, como a função K de Ripley. 2004. 79f. Dissertação (Mestrado em Ecologia de Agroecossistemas) - Escola Superior de Agricultura "Luiz de Queiroz”, Universidade de São Paulo, USP, São Paulo, 2004. 
CARVALHO, P. E. R. Espécies florestais brasileiras: recomendações silviculturais, potencialidades e uso da madeira. Brasília: Embrapa/CNPF; Embrapa/ SPI, Brasília, Brasil, 1994. 640 p.

CHANG, M. Y. Sistema Faxinal: Uma forma de organização camponesa em desagregação no Centro Sul do Paraná. Londrina: IAPAR, 1988. (Boletim Técnico, 22).

CONSULTORIA E DESENVOLVIMENTO DE SISTEMAS LTDA - CIENTEC Software Mata Nativa 2: Sistema para análise fitossociológica e elaboração de inventários e planos de manejo de florestas nativas. Viçosa, MG, 2006.

EMPRESA BRASILEIRA DE PESQUISA AGROPECUÁRIA - EMBRAPA. Serviço Nacional de Levantamento e Conservação de Solos. Levantamento de reconhecimento dos solos do Estado do Paraná. Londrina: EMBRAPA-SNLCS / SUDESUL / IAPAR, 1984. 2 v. (EMBRAPA-SNLCS. Boletim de Pesquisa, 27; IAPAR. Boletim Técnico, 16).

EMPRESA BRASILEIRA DE PESQUISA AGROPECUÁRIA - EMBRAPA. Centro Nacional de Pesquisa de Solos. Sistema brasileiro de classificação de solos. Rio de Janeiro, Brasil, 1999. 412 p.

FUNDAÇÃO DE PESQUISA EM ENGENHARIA FLORESTAL - FUPEF. Mapeamento e quantificação de áreas de estágios sucessionais da Floresta Ombrófila Mista no Estado do Paraná. Curitiba: 2001. 75p. (Relatório de Pesquisa não publicado).

GUBERT FILHO, A. O Faxinal. Direito Agrário e Meio Ambiente. Curitiba: [S.I.], 1987. $34 \mathrm{p}$.

KLEIN, R. M. Importância prática da fitossociologia para a silvicultura Sul-Brasileira. Boletim Paranaense de Geografia, Curitiba, n. 10, 11, 12, 13, 14, 15, p. 269-280.

LONGHI, S. J. A estrutura de uma floresta natural de Araucaria angustifolia (Bert.) O. Ktze, no sul do Brasil. 1980. 198f. Dissertação (Mestrado em Engenharia Florestal) Universidade Federal do Paraná, UFPR, Curitiba, 1980.

LONGHI, S.J.; BRENA, D. A.; GOMES, J. F.; NARVAES, I. S.; BERGER, G.; SOLIGO, A. J. Classificação e caracterização de estágios sucessionais em remanescentes de Floresta Ombrófila Mista. Ciência Florestal, Santa Maria, v. 16, n.2, p. 113-125, 2006.

MEYER, H. A. Structure, growth, and drain in balanced uneven-aged forests. Journal of Forestry, Oxford, v. 50, p. 85-92, 1952.

MUELLER-DOMBOIS, D.; ELLENBERG, H.Aims and methods of vegetation ecology. New York: John Wiley e Sons, 1974. 547 p.

NASCIMENTO, A. R. T.; LONGHI, S. J.; BRENA, D. A. Estrutura e padrões de distribuição espacial de espécies arbóreas em uma amostra de Floresta Ombrófila Mista em Nova Prata, RS. Ciência Florestal, Santa Maria, v. 11, n.1, p. 105-119, 2001. 
PARANÁ. Secretária de Estado de Agricultura e Abastecimento, Instituto de Terras, Cartografia e Florestas. Atlas do Estado do Paraná. Curitiba: 1987. 73 p.

PARANÁ. Decreto Estadual n. 3466 de 14 de agosto de 1997. Dispõe as ARESUR - Áreas Especiais de Uso Regulamentado. Diário Oficial [do] Paraná, Curitiba, 1997.

PAYANDEH, B. Comparison of method for assessing spatial distribution of trees. Forest Science, Bethesda, v. 16, p. 312-317, 1970.

PIELOU, E. C. Mathematical ecology. New York: Wiley, 1977. 385 p.

RAMOS, P. H. X. et al. Diversidade e Estrutura diamétrica de um remanescente de floresta ombrófila mista aluvial no município de Lages, SC. In: SIMPÓSIO LATINO AMERICANO SOBRE MANEJO FLORESTAL, 4., 2008, Santa Maria. Anais... Santa Maria: UFSM, CCR, Programa de Pós-Graduação em Engenharia Florestal,2008.p.184-189.

RIO GRANDE DO SUL Secretaria Estadual do Meio Ambiente. Inventário Florestal Contínuo do Rio Grande do Sul. Santa Maria: SEMA/ UFSM, 2002. 706p. (Relatório).

SILVA, M. A contribuição de Florestas com Araucária para a sustentabilidade dos sistemas Faxinais. 2005. 102f. Dissertação (Mestrado em Engenharia Florestal) Universidade Federal do Paraná, Curitiba, 2005.

SHANNON, C. E.; WIENER, W. The mathematical theory of communication. Urbana. Illinois: University of Illinois Press, 1949. 117 p.

SUDERHSA. Superintendência de Desenvolvimento de Recursos Hídricos e Saneamento Ambiental. Atlas de Recursos hídricos do estado do Paraná. Curitiba: 1998. 38 p.

SAWCZUK, A. R. Florística e estrutura horizontal no período 2002-2008 de um fragmento de Floresta Ombrófila Mista no centro-sul do estado do Paraná. 2009. $139 \mathrm{f}$. Dissertação (Mestrado em Engenharia Florestal) - Universidade Estadual do Centro-Oeste, Paraná, 2009.

WATZLAWICK, L. F.; ALBUQUERQUE, J. M.; SILVESTRE, R.; VALÉRI, A. F.; KOEHLER, H. S.; SAUERESSIG, D. Estrutura vertical na floresta ombrófila mista em Sistema Faxinal no município de Rebouças, PR. In: SIMPÓSIO LATINO AMERICANO SOBRE MANEJO FLORESTAL, 4., 2008, Santa Maria. Anais... Santa Maria: UFSM, CCR, Programa de Pós-Graduação em Engenharia Florestal, 2008. p.152-158. 